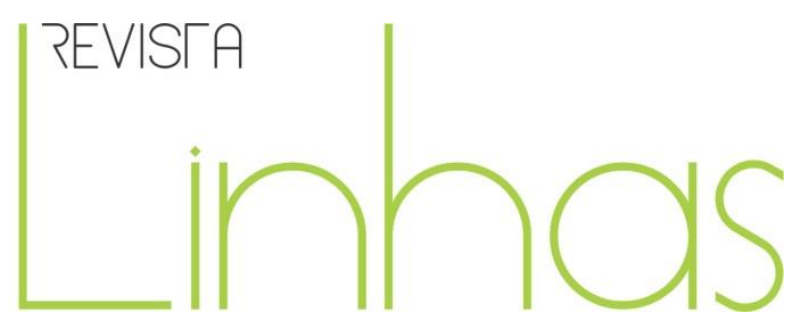

\title{
Sobre o sentido político do ensino de música na educação escolar: das relações entre a arte e a realidade objetiva ${ }^{1}$
}

\begin{abstract}
Resumo
Este artigo tem por objetivo abordar fundamentos teóricos que subsidiem as discussões sobre as implicações políticas do ensino da música na educação escolar. Pretendemos demonstrar que o entendimento das especificidades estéticas da arte e da música como produções humanas é essencial para que se compreenda o sentido político da educação musical. Para tanto, partimos inicialmente da discussão empreendida por Dermeval Saviani sobre as relações entre a educação e a política, que nos esclarece o papel dos conteúdos escolares. Assim, para entender o caráter específico da música como um desses conteúdos, analisamos a arte e a música como reflexos da realidade objetiva, sob a fundamentação da epistemologia e da estética proveniente do materialismo histórico-dialético. Concluímos defendendo que o sentido político do ensino da música deve ser buscado, acima de tudo, nos elementos propriamente musicais e na forma como esses elementos proporcionam uma determinada concepção de mundo ao aluno. Daí, portanto, a necessidade da compreensão das especificidades da música e de sua relação com a realidade objetiva.
\end{abstract}

Palavras-chave: Educação Musical. Política. Estética Marxista. György Lukács. Pedagogia Histórico-Crítica.
Thiago Xavier de Abreu

Universidade Estadual de Ponta

Grossa - UEPG - Ponta Grossa/PR

- Brasil

parathiagoxavier@gmail.com

\section{Newton Duarte}

Universidade Estadual Paulista -

UNESP - Araraquara/SP - Brasil

newton@fclar.unesp.br

\footnotetext{
Para citar este artigo:

ABREU, Thiago Xavier de; DUARTE, Newton. Sobre o sentido político do ensino de música na educação escolar: das relações entre a arte e a realidade objetiva. Revista Linhas. Florianópolis, v. 20, n. 42, p. 12-35, jan./abr. 2019.
}

DOI: $10.5965 / 1984723820422019012$

http://dx.doi.org/10.5965/1984723820422019012

\footnotetext{
${ }^{1}$ Trabalho resultante de pesquisa executada com apoio financeiro da CAPES.
} 


\title{
About the political meaning of music education in school education: the relationship between art and the objective reality
}

\begin{abstract}
This article aims to address theoretical foundations that support discussions about the political implications of music teaching in school education. We intend to demonstrate that the understanding of the aesthetic specificities of art and music as human productions is essential for understanding the political meaning of musical education. To do so, we start from the discussion made by Dermeval Saviani about the relationship between education and politics, which clarifies the role of school contents. Thus, in order to understand the specific character of music as one of these contents, we analyze art and music as reflections of objective reality, under the foundation of epistemology and aesthetics derived from historicaldialectical materialism. We conclude by arguing that the political meaning of music teaching should be sought above all in the musical elements themselves and in the way in which these elements provide a particular conception of the world to the student. Hence, therefore, the need to understand the specificities of music and its relation to objective reality.
\end{abstract}

Keywords: Music Education. Politics. Marxist Aesthetics. György Lukács. Historical Critical Pedagogy. 


\section{Introdução}

A concepção de que o ensino da música possa ter efeitos na vida política da sociedade não é uma novidade. Para o pensamento clássico grego, por exemplo, não havia dúvidas de que a música influenciava dimensões éticas e morais do ser humano e, portanto, era um elemento indispensável para a formação política do cidadão, como já largamente discutido na musicologia (BOURGAULT, 2012; SCHRADE, 1947; MATHIESEN, 1984). No atual momento histórico brasileiro, as relações entre a política e a educação novamente ganham destaque nas discussões pedagógicas, principalmente naquelas cujo objeto é a educação escolar. O entendimento da escola como uma instituição localizada no seio da sociedade e que, portanto, se configura como um local de disputa de forças sociais antagônicas, fica cada vez mais evidente: na mesma medida em que as tendências mais reacionárias tentam penetrar no ambiente escolar institucionalizando seus interesses por vias como o projeto “Escola sem Partido", esforços vêm sendo empreendidos no sentido de compreender melhor as relações entre a escola e a política.

O presente trabalho visa somar-se a esses esforços, abordando fundamentos teóricos que subsidiem as discussões sobre as implicações políticas do ensino da música na educação escolar. Pretendemos defender a seguinte tese: a compreensão das especificidades da música como objetivação humana contribui para o entendimento da dimensão política do seu ensino, pois a prática educativa e a prática política não se identificam, mas estão unidas por muitos laços nem sempre facilmente perceptíveis. Em outras palavras, nossa intenção é demonstrar que o entendimento das peculiaridades da música como uma atividade específica da prática social pode nos ajudar a apreender o sentido político da educação musical na escola e, desta forma, direcionar sua prática pedagógica sob o horizonte da superação das contradições sociais que atualmente vivemos.

\section{O que é uma educação politizada?}

Se pretendemos discutir o sentido político da educação musical na escola, devemos primeiro compreender como se relacionam os fenômenos educacional e político. Somente assim, podemos realmente compor uma perspectiva para a orientação 
de uma prática pedagógica politizada. Em seu texto Onze teses sobre educação e política, Dermeval Saviani (2008a) trata dessas duas “modalidades específicas" da prática social (idem, p. 68). Partindo da ideia de que a educação e a política sejam fenômenos sociais necessariamente ligados um ao outro, porém distintos entre si, o autor discute a natureza de suas especificidades.

Saviani nos explica que a diferença essencial entre a prática pedagógica e a prática política está no fato de que a primeira se trata de uma relação entre não-antagônicos, ao passo que a segunda se dá em uma relação de antagonismo entre seus agentes. Na educação, em última instância, pressupõe-se que o educador esteja a favor do educando, isto é, que sua ação colabore para os interesses do aluno, que se direcionem para o bem do aprendiz. Já em qualquer relação política os interesses entre seus agentes são, no limite, essencialmente diferentes, mutuamente excludentes, antagônicos, constituindo uma disputa de forças contrária uma a outra.

Entretanto, por mais que sejam atividades necessariamente distintas uma da outra, toda prática pedagógica tem uma dimensão política e também toda prática política tem uma dimensão pedagógica. Essas relações entre a educação e a política podem ser entendidas em um sentido externo e em um sentido interno. No sentido externo, trata-se de constatar que ambas "têm existência histórica; logo, só podem ser adequadamente compreendidas enquanto manifestações sociais determinadas" (SAVIANI, 2008 a , p. 68). Ou seja, que as relações entre a educação e a política estão inseridas em um contexto histórico que promove uma "subordinação relativa mas real da educação diante da política" (idem, p. 69); podemos observar essa subordinação, por exemplo, na necessidade de investimentos públicos na educação, algo que depende da prática política. Já do ponto de vista interno, levando-se em conta a educação e a política em si mesmas, temos a seguinte situação:

A dimensão política da educação consiste em que, dirigindo-se aos nãoantagônicos a educação os fortalece (ou enfraquece) por referência aos antagônicos e desse modo potencializa (ou despotencializa) a sua prática política. E a dimensão educativa da política consiste em que, tendo como alvo os antagônicos, a prática política se fortalece (ou enfraquece) na medida em que, pela sua capacidade de luta, ela convence os nãoantagônicos de sua validade (ou não-validade) levando-os a se engajarem (ou não) na mesma luta. 
A dimensão pedagógica da política envolve, pois, a articulação, a aliança entre os não-antagônicos visando à derrota dos antagônicos. E a dimensão política da educação envolve, por sua vez, a apropriação dos instrumentos culturais que serão acionados na luta contra os antagônicos. (SAVIANI, 2008 ${ }^{\mathrm{a}}$, p. 68))

A dimensão política da educação reside no fato de que a socialização das produções culturais mais ricas e desenvolvidas nos campos das artes, da ciência e da filosofia é condição necessária, ainda que não suficiente, para o desenvolvimento da consciência da classe trabalhadora, realizando-se o movimento de passagem da condição de classe em si à de classe para si. Ora, a especificidade da educação escolar consiste exatamente na organização de processos sistemáticos de ensino que permitam a universalização da apropriação dos instrumentos culturais necessários à superação por incorporação das formas elementares de compreensão da natureza, da sociedade e da vida humana. Nesse sentido, a prática pedagógica não se torna política pela inclusão entre seus conteúdos, de temas explicitamente políticos ou que sejam alvo declarado de conflitos ideológicos. Na verdade, a prática pedagógica é sempre política porque, em última instância, nela estão em disputa duas direções opostas: uma que se empenha em fazer com que a educação escolar universalize de fato o domínio da cultura em suas formas mais ricas, o que poderíamos chamar de desprivatização da cultura, e outra que mobiliza recursos materiais e ideológicos no sentido de manter a educação escolar aprisionada à função de reprodução da divisão social do trabalho e da alienação. Se essa função política intrínseca à educação escolar não for compreendida em todos seus desdobramentos, as forças progressistas em educação correm o risco de contribuir, involuntariamente, para o que desejam as forças reacionárias no campo educacional, ou seja, manter a classe trabalhadora apartada do domínio das ferramentas culturais necessárias ao combate aos muitos disfarces que acobertam as relações sociais de exploração e de opressão.

É por esse motivo que Saviani (2008a, p. 72) chega à conclusão que "a função política da educação cumpre-se na medida em que ela se realiza como prática especificamente pedagógica". Isso quer dizer que quanto mais a prática educacional estiver voltada para a sua especificidade como prática social, a especificidade pedagógica, mais ela se potencializa como uma prática política. 
Dessa maneira, pensar a educação escolar como um agente político significa, entre outras coisas, compreender como seus conteúdos curriculares, em relação dialética com as formas didáticas, contribuem para a formação do indivíduo. A análise do sentido político do ensino da música nas escolas pode, então, partir do seguinte questionamento: a explicitação das especificidades da música como prática social pode contribuir para o entendimento do sentido político de seu ensino? As discussões a seguir visam fornecer subsídios para o entendimento dessa problemática, bem como a resposta a essa pergunta compõe a tese que aqui defendemos.

\title{
3. A música como reflexo da realidade objetiva: do caráter mediado entre a objetividade e a obra
}

Para a caracterização das especificidades da música como prática social - e, consequentemente, para o entendimento do seu sentido político - primeiramente, devemos observá-la de maneira mais ampla, como uma atividade artística. Em seus escritos estéticos, György Lukács (1966a, 1966b, 1967a, 1967b, 1968, 2010) nos fornece elementos para esta análise. O filósofo húngaro considera que a arte é um reflexo da realidade objetiva, assim como a ciência e outras formas de consciência da realidade.

\begin{abstract}
Uma tese fundamental do materialismo dialético sustenta que qualquer tomada de consciência do mundo exterior não é mais do que o reflexo da realidade, que existe independentemente da consciência, nas ideias, representações, sensações, etc. dos homens. É claro que o materialismo dialético, que na formulação geral deste princípio concorda com todos os tipos de materialismo e se opõe a todas as variantes do idealismo, é diferente do materialismo mecanicista. Quando Lenin criticava sobre isso o velho materialismo, insistia precisamente neste motivo fundamental, ou seja, o de que o velho materialismo não estava em condições de conceber dialeticamente a teoria do reflexo. (LUKÁCS, 2010, p. 23)
\end{abstract}

Lukács foi um filósofo marxista e, portanto, sua obra tem como fundamento teórico basilar o materialismo histórico-dialético. Sua teoria estética parte da análise do fenômeno artístico à luz da tese da prioridade ontológica da realidade objetiva frente à consciência, ou, que a realidade existe em si independentemente do que ela é para nós. Assim, num sentido mais geral, toda forma de consciência, inclusive a arte, não pode ser outra coisa senão a reprodução da realidade objetiva na subjetividade. 
Para o entendimento desse processo de reprodução da realidade objetiva na subjetividade, destaca-se a contribuição da psicologia histórico-cultural. Uma vez que também é fundamentada no materialismo histórico-dialético, esta corrente da psicologia entende que o psiquismo humano não nasce de fenômenos puramente subjetivos, mas sim são apropriações de funções sociais que existem objetivamente. Por isso, na visão da escola psicológica iniciada por Vygotski, o psiquismo pode ser entendido como a imagem subjetiva da realidade objetiva. De acordo com Martins (2013, p. 31):

ao afirmar o método materialista dialético como requisito para o estudo do homem concreto, isto é, em suas múltiplas determinações, a psicologia soviética anunciou a possibilidade científica de explicação do psiquismo como, ao mesmo tempo, estrutura orgânica e imagem subjetiva da realidade, correlacionando fenômenos psíquicos e mundo material. Essa abordagem viabilizou a superação de interpretações fragmentárias e dicotômicas entre experiência interna e externa, entre subjetividade e objetividade, entre indivíduo e sociedade, dentre outras.

Não adentraremos aqui essa dimensão psicológica da formação de uma imagem subjetiva da realidade objetiva. Basta, para nós, destacarmos o diálogo entre as proposições estéticas de Lukács e a teoria erigida pela psicologia soviética. Tanto o filósofo húngaro quanto essa corrente da psicologia tomam como referencial a mesma fundamentação filosófica (marxismo), bem como seu princípio epistemológico central, o de que a realidade objetiva existe independentemente da consciência. Consequentemente, seus posicionamentos acerca da consciência humana convergem no sentido de entendê-la como um reflexo da realidade objetiva.

Entender a consciência como um reflexo da realidade objetiva na subjetividade não significa, contudo, tomá-la como uma reprodução direta e mecânica. A suposição de que o reflexo da realidade objetiva na consciência deva ser uma mera cópia, uma recepção passiva da realidade por parte do sujeito, é completamente estranha à dialética do marxismo, como indicado por Lukács na citação acima em sua crítica ao materialismo que precedeu a obra de Karl Marx. A concepção de reflexo no marxismo parte da dialética entre subjetividade e objetividade, indivíduo e sociedade, consciência e realidade objetiva; mas, principalmente, parte do princípio geral da atividade humana, do trabalho, da prática social como fundadora do mundo humano. 
A análise das relações entre objetividade e subjetividade empreendida pelos autores do materialismo histórico-dialético deriva precisamente desta centralidade da categoria de trabalho, que sintetiza os diferentes aspectos da atividade propriamente humana. Uma das formas que a teoria marxista observa as especificidades da atividade humana é considerá-la a partir da dialética entre os processos de apropriação dos elementos da realidade objetiva para o atendimento das necessidades dos seres humanos e da objetivação de propriedades humanas nos produtos dessa atividade.

Fundamentando-se em obras de Marx e da tradição marxista, Duarte (2013, p. 2154) realiza um estudo dessa relação dialética. Como nos mostra o autor, a vida dos seres humanos, assim como a dos outros animais, caracteriza-se por ser um processo ativo. Tais ações sobre a realidade estão direcionadas por necessidades, que podem ser dadas tanto pelo meio no qual um animal vive, quanto por fatores genéticos - tome-se, por exemplo, a necessidade de mamar, típica dos mamíferos. Mas ao passo que os outros animais simplesmente atendem a tais necessidades, numa relação direta atividade/necessidade, os seres humanos se diferenciam por apropriarem-se da realidade objetiva para construir os meios de satisfação dessas necessidades. Nesse processo de construção, o ser humano transforma a natureza "pura" em uma natureza humanizada, objetivando-se nos produtos de sua atividade; ou melhor, os produtos de sua ação sobre a natureza constituem-se como atividade humana objetivada. A relação direta entre necessidade e atividade passa, no ser humano, a ser uma relação mediada pela própria atividade, agora tornada algo fixado na realidade objetiva, fixado nos produtos do trabalho. Uma vez transformada a realidade objetiva, a experiência humana dessa "nova" realidade também será diferente, direcionando novas necessidades e, assim, novas formas da dinâmica entre apropriação e objetivação. Daí a historicidade da prática social, ou, nas palavras de Saviani, o fato de que "diferentemente dos outros animais, que se adaptam à realidade natural tendo sua existência garantida naturalmente, o homem necessita produzir continuamente sua própria existência" (SAVIANI, 2008b, p. 11).

Partindo dessas considerações acerca das especificidades da atividade propriamente humana, voltemos à problemática das relações entre objetividade e subjetividade. Para o materialismo histórico-dialético é a prática social que constrói a realidade humana e, sendo a subjetividade um elemento dessa realidade, pode-se 
concluir que é justamente por meio do trabalho que o ser humano forja socialmente sua subjetividade. Contudo, esse processo de autoconstrução não surge magicamente do interior do próprio ser humano, mas sim das necessidades objetivas, as quais direcionam a dinâmica de apropriação e objetivação da atividade humana. Uma vez que tais necessidades também são frutos do trabalho, então, elas também se transformam, isto é, são históricas. Assim, não precisamos ir além desses pressupostos para constatar que a reprodução da objetividade na subjetividade humana não pode ser um processo mecânico, de simples transposição direta da objetividade à subjetividade. Existe todo um movimento vivo, uma constante tensão entre a atividade do indivíduo e a objetividade socialmente construída, entre as singularidades biográficas de uma pessoa e o processo geral de desenvolvimento do gênero humano. Por isso, um reflexo verdadeiro da realidade compreende-a em movimento, o que implica o entendimento tanto de suas configurações atuais, como de sua história e de suas alternativas possíveis de futuro. É nesse sentido que Karel Kosik afirma que a consciência é uma unidade de reflexo e projeto:

A práxis humana se manifesta, além disso, também sob um outro aspecto: ela é o cenário onde se opera a metamorfose do objetivo no subjetivo e do subjetivo no objetivo, ela se transforma no centro ativo onde se realizam os intentos humanos e onde se desvendam as leis da natureza. A práxis humana funde a causalidade com a finalidade. Mas se partirmos da práxis humana como da fundamental realidade social, de novo descobrimos que também na consciência humana, sobre o fundamento da práxis e em uma unidade indissolúvel, se formam duas funções essenciais: a consciência humana é ao mesmo tempo registradora e projetadora, verificadora e planificadora: é simultaneamente reflexo e projeto. (KOSIK, 1976, p. 114)

Compreendida a concepção de reflexo do materialismo histórico-dialético a partir da dialética entre objetividade e subjetividade, devemos agora entender algumas especificidades da arte como um reflexo da realidade objetiva. Longe de serem meras cópias da realidade, as obras de arte são reflexo ativo da realidade e elementos constitutivos dessa mesma realidade, como novamente explica Kosik:

O caráter dialético da práxis imprime uma marca indelével em todas as criações humanas. Logo também sobre a arte. Uma catedral da Idade Média não é apenas imagem do mundo feudal, é ao mesmo tempo um elemento da estrutura daquele mundo. Não só reproduz artisticamente a 
realidade da Idade Média, mas ao mesmo tempo também a produz artisticamente. Toda obra de arte apresenta um duplo caráter em indissolúvel unidade: é expressão da realidade, mas ao mesmo tempo cria realidade, uma realidade que não existe fora da obra ou antes da obra, mas precisamente apenas na obra. (KOSIK, 1976, p. 115, itálicos no original)

Nas palavras de Lukács (1968, p. 258), “surge assim na obra de arte um 'mundo próprio', um mundo particular no sentido literal da palavra, uma individualidade da obra". Na criação artística, as experiências e objetos de nossa vida cotidiana são elevados a um mundo particular, a obra de arte, um meio homogêneo no qual toda a heterogeneidade é suspensa e reordenada sob suas próprias leis, as quais não têm nenhuma obrigação de condizer - pelo menos internamente - com a realidade objetiva, fazendo com que os fenômenos façam sentido uns com os outros.

Desta maneira, "se dois pintores figuram diversamente a mesma paisagem ou retratam diversamente a mesma pessoa, não existe contradição no sentido indicado" (LUKÁCS, 1968, p. 243). No caso da arte, não há como falar que uma obra está mais certa ou errada do que a outra da mesma forma como fazemos tal julgamento no reflexo científico. Isso não quer dizer, contudo, que ambas as obras tenham o mesmo valor artístico, que não possamos comparar uma à outra e julgar qual obra é mais rica, isto é, qual delas reflete de forma mais profunda o conteúdo da realidade objetiva. Uma obra de arte pode e deve ser comparada à outra em termos de valor artístico, principalmente do ponto de vista educacional, no qual é necessário que selecionemos os conteúdos mais ricos para a formação humana, mas essa comparação deve considerar os parâmetros próprios do reflexo estético.

É essencial que compreendamos esta contradição dialética entre a obra de arte a realidade objetiva: por um lado, devemos tomar o princípio da individualidade da obra de arte como elemento central de qualquer análise estética; por outro, tal individualidade não é nada mais do que uma especificidade da arte como reflexo da realidade objetiva. Em outras palavras, o reflexo estético tem total autonomia formal perante a realidade, mas essa autonomia é determinada precisamente pela justeza entre o conteúdo da obra e o conteúdo da realidade objetiva. Essa contradição se expressa de maneira aguda 
quando se tenta extrair o valor artístico de uma obra levando-se em conta o quanto ela é “parecida” com a realidade objetiva. Para Lukács (1967b, p. 26):

O problema do "parecido" experimenta, então, uma intensificação e aprofundamento dialéticos: a nova imediatez da obra de arte, que supera e restabelece a imediatez da vida cotidiana, se distancia, por um lado, daquele "modelo" reproduzido da vida cotidiana que lhe dá forma, e pode até mesmo representar um mundo fantástico que, diretamente considerado, não tenha modelo algum na vida. Por outro lado, precisamente isso permite acentuar muito mais e fazer evocador o "parecido" do artisticamente refletido com os momentos essenciais da evolução da humanidade.

Quanto mais a arte se aproxima da realidade maior é sua riqueza de conteúdo e, consequentemente, sua importância na prática social. Uma obra de arte deve ser um reflexo o mais "parecido" possível com a realidade objetiva, mas isso não se assemelha nem um pouco com o que consideramos ser algo "parecido" no senso comum. A natureza específica do objeto estético faz com que uma obra possa penetrar profundamente nos fenômenos da vida mesmo que não se assemelhe em nada com a realidade objetiva imediatamente dada. Mais do que isso: é justamente nessa liberdade de distanciamento perante a realidade objetiva imediata permitida pela individualidade da obra que ela se aproxima da realidade objetiva, que se torna "parecida" com ela. Assim, um conto completamente fantasioso que narra um mundo fantástico pode ser mais "parecido" com o real do que a nossa própria experiência cotidiana, por exemplo. Isso porque na obra de arte está sintetizada a essência da realidade, ao passo que na vida cotidiana é comum que nos limitemos à experiência superficial e epidérmica do real. A questão do "parecido", que em muitas teorias estéticas acaba por suscitar contradições insolúveis, é resolvida dialeticamente na teoria do reflexo sem prejuízo tanto para a obra quanto para a realidade objetiva que a serviu de modelo.

No caso da música, a problemática do "parecido" torna-se ainda mais intensificada. Os elementos estéticos propriamente musicais, como as notas e seus princípios de organização, à primeira vista parecem não ter nenhuma relação com a realidade objetiva. De fato, basta nos perguntarmos qual é o conteúdo de uma sinfonia de Beethoven ou de um tema de Thelonious Monk para colocarmos em xeque toda a concepção de reflexo. Daí o porquê de, historicamente, grande parte dos estudos 
estéticos que tentaram explicar o fenômeno musical atribuírem aos elementos musicais uma total autonomia perante a realidade concreta: na Grécia antiga, acreditava-se que a música era uma manifestação "pura" da essência metafísica da realidade, uma vez que possuía uma organização matemática que emana de suas próprias características, assim como a natureza (BOURGAULT, 2012; SCHRADE, 1947; MATHIESEN, 1984, GROUT, PALISCA, 1994); já na produção musical contemporânea, atribui-se um valor estético imanente ao som em si mesmo, como sintetizado pelas concepções de objeto sonoro (SCHAEFFER, 1988) e de paisagem sonora (SCHAFER, 1991, 2011).

Porém, do ponto de vista do materialismo histórico-dialético não podemos considerar que os elementos propriamente musicais estejam deslocados da realidade objetiva. Não podemos atribuir uma autonomia total da música perante a realidade, como se seu conteúdo emanasse exclusivamente dos princípios organizacionais de seus elementos. Tal distanciamento da realidade imediata e cotidianamente observável, que de fato existe, não significa que a música não se relacione com a realidade objetiva, que não seja um reflexo dela. A dificuldade para a resolução dialética da problemática do "parecido" na música está em perceber que esse distanciamento perante a realidade, tão característico dos elementos musicais, nada mais é do que a forma especificamente musical de refletir determinado conteúdo da vida humana.

Ao passo que em todas as outras artes a questão da negação das formas imediatas da realidade como determinação do conteúdo da obra se constitui num dos vários momentos da composição do reflexo artístico, na música, esse princípio é transformado em núcleo da organização do reflexo, em essência da instituição do objeto musical em seu conteúdo e forma. Observando deste prisma de uma negação como determinação, toda falsa contraposição entre a música e objetividade da vida se dissolve.

A notável simultaneidade de um ultra distanciamento da vida e uma ultra proximidade da vida, que é própria da música, se esclarece assim por si mesma. Pois sua distância com relação à vida, o fato de que seu meio homogêneo não tenha imediatamente nada a ver com a realidade objetiva dada e que, portanto, não aparece sequer imediatamente como mimese sua, se funde por si mesmo com sua proximidade à vida, com o fato de que aparentemente enuncia sem mediação alguma a essência mais subjetiva e interna do homem; tudo isso fica claro se se parte da indicada negação como determinação. (LUKÁCS, 1967b, p. 44) 
Para Lukács, esse traço tão característico da música significa precisamente a sua forma específica de aproximação da realidade objetiva. Isso porque, para o filósofo, a objetivação musical é uma prática social que se desenvolveu para refletir a vida interior humana; para torná-la algo objetivo e, assim, possibilitar que as pessoas se relacionem objetivamente com a interioridade humana, que passa a existir numa forma peculiar de objetos externos, que são as obras musicais. A dimensão mais profunda da interioridade do ser humano é formada pelos seus sentimentos e emoções perante o mundo, pelas suas reações afetivas perante os fatos da vida. Assim, a música não reflete a realidade objetiva por si mesma, mas sim a vida afetiva do ser humano. Não é um reflexo voltado "para fora”, mas sim "para dentro", isto é, para uma objetividade que já se internalizara de tal forma na subjetividade do indivíduo que não pode ser mais diretamente relacionada à realidade imediatamente dada senão por meio das reações afetivas, senão pela movimentação anímica dos sentimentos e emoções em uma vivência afetiva.

De certa forma, todas as artes refletem a vida interior humana; todas as expressões artísticas têm como conteúdo elementos da subjetividade do ser humano e, consequentemente, possuem necessariamente um caráter emocional e afetivo. Daí que em todas as artes também esteja presente a problemática do "parecido". Mas, uma vez que o conteúdo refletido na música praticamente se limita a tal interioridade humana, sua relação com a realidade objetiva torna-se altamente mediada: sua negação radical de qualquer forma existente imediatamente na realidade objetiva é justamente o que possibilita a criação de um meio homogêneo que supera todas as formas cotidianas de sentimentos e emoções e, nas palavras de Lukács acima, "enuncia sem mediação alguma a essência mais subjetiva e interna do homem".

\section{Conclusão: implicações das especificidades da música para uma educação politizada}

Considerando tais reflexões estéticas acerca do objeto musical e de suas relações com a realidade objetiva, iluminamos por novos ângulos a problemática do sentido político do ensino da música. É comum encontrarmos posicionamentos que consideram que a música, para elevar o ouvinte/aluno à consciência das problemáticas da realidade 
objetiva, deve refletir o mais precisamente possível essa realidade. Quanto a isso, concordamos. Mas em que consiste tal precisão?

Muitas das concepções pedagógicas acerca desse tema observam a relação entre a música e a realidade objetiva de maneira relativamente superficial, isto é, sem considerar as especificidades do objeto musical, acarretando em dificuldades para o entendimento do sentido político da educação musical. Um exemplo disso está na perspectiva que identifica somente nas canções de cunho político a capacidade de atuar de forma transformativa na vida do aluno, considerando que uma música, para ser efetiva na vida política, deve expor diretamente as mazelas sociais, algo como um retrato jornalístico de determinadas problemáticas de nossa sociedade. Contudo, uma análise estética mais profunda chegará à conclusão de que o fundamento máximo de qualquer efeito estético é a individualidade da obra, sua relativa autonomia perante a realidade imediata, e que não necessariamente uma canção que se limite a narrar o cotidiano será mais politicamente ativa do que uma cujas imagens sejam fantasiosas; nas palavras de Lukács (2010, p. 24), se toda a arte se constitui como um reflexo da realidade, "essa realidade não é somente a superfície imediatamente percebida do mundo exterior, não é a soma dos fenômenos eventuais, casuais e momentâneos". Entretanto, pretendemos abordar aqui essa problemática de um prisma ainda mais profundo, questionando a própria limitação dessas perspectivas pedagógicas à forma musical de uma canção, o que leva essas concepções a serem incapazes de ver um sentido político no ensino dos elementos especificamente musicais, como as notas e sua estrutura de organização.

A canção, como uma forma artística que surge da união entre a música e a poesia, pode levar algumas dificuldades ao estudo das relações entre a obra de arte e a realidade objetiva e, consequentemente, no entendimento do sentido político do ensino da música. À luz das reflexões anteriormente apresentadas, a raiz dessas possíveis dificuldades fica clara: a poesia, diferentemente da música, se constitui como um reflexo artístico que toma seus objetos da realidade objetiva aparente, observável, organizando-os de tal forma a refletir as tensões e contradições historicamente criadas pela vida do ser humano. Para Lukács (1967b, p. 34-35), a poesia 
reflete a trajetória temporal concreta e, como tal, precisamente em sua historicidade, em sua dialética objetiva de nascer e perecer, de continuidade e descontinuidade, e de tal modo que sempre tomam forma a realidade objetiva e seus reflexos subjetivos na vida interior humana (...) Isto é: trata-se sempre de reproduzir poeticamente os fatos objetivos da vida que desencadeiam reflexos na vida interior do homem e as refigurações subjetivas produzidas por eles na interioridade do homem representado.

Uma vez que mais diretamente relacionada com a realidade objetiva imediatamente dada, seu sentido político tende a ficar mais imediatamente exposto. $\mathrm{O}$ direcionamento estético de uma obra poética está baseado na "trajetória temporal concreta", isto é, na maneira como as contradições do desenvolvimento histórico da humanidade tomam forma na realidade objetiva exterior. A poesia mobiliza esses elementos para criar um determinado efeito na vida interior do ser humano, levando-o a sentir aquelas contradições como suas, como parte de sua vida. Assim, as relações entre a realidade objetiva e o efeito estético proporcionado pela obra são mais diretamente perceptíveis na obra poética. Em outras palavras, é mais fácil relacionar o conteúdo de uma poesia e a realidade objetiva e, dessa forma, entender como esse conteúdo pode direcionar um efeito estético que culminará em determinados direcionamentos políticos da prática social.

Por exemplo: no Brasil, é quase um senso comum considerar que a música de Chico Buarque pode levar o ouvinte ao entendimento das problemáticas do cotidiano, e que isso pode influenciar a consciência política desse indivíduo. Porém, quase a totalidade desses posicionamentos se refere à dimensão poética das canções de Chico, ou seja, à forma profunda e altamente elaborada como as letras de suas músicas refletem a essência do nosso dia-a-dia. De fato, um dos principais fatores que garantem a riqueza artística das músicas desse compositor está ligado à maneira como sua poesia direciona determinados sentimentos e emoções sobre os acontecimentos da nossa vida, podendo, assim, culminar em posturas políticas frente a eles. Mas se nosso intuito neste trabalho é entender como a música pode influir na transformação da concepção de mundo de uma pessoa, alçando, dessa maneira, o sentido político de seu ensino, devemos ir além dos aspectos poéticos contidos em uma canção, observando as relações entre os elementos propriamente musicais e a realidade objetiva. 
Com esse exemplo não pretendemos diminuir a importância da poesia de Chico Buarque no efeito de sua música, nem tampouco avançar no estudo estético da relação entre elementos propriamente musicais de sua canção e a realidade objetiva, algo que ultrapassaria em muito os limites deste trabalho. Somente utilizamos sua obra para destacar uma necessidade que se impõe à investigação do sentido político do ensino da música: a indispensabilidade de partir esta análise das especificidades da música como um reflexo estético, ou seja, da relação entre os elementos propriamente musicais e a realidade objetiva. Uma análise que tente buscar tal sentido político em elementos extramusicais, que não se fundamente na ideia de que a música, por si mesma, é um reflexo da realidade objetiva, e que não compreenda a natureza desse reflexo, pode acabar por entender que outras formas musicais ou mesmo o ensino dos elementos da música são coisas deslocadas da realidade objetiva, empalidecendo também sua dimensão política.

É o que ocorre, por exemplo, com o ensino da notação musical. Qual seria a dimensão política do ensino da escrita e da leitura da música? Para respondermos a tal indagação, devemos primeiramente partir da concepção de que a música é uma atividade de objetivação da vida interior humana e, portanto, tem uma historicidade determinada por sua necessidade como prática social, desenvolvendo-se historicamente junto com a sociedade. É sabido também que as transformações da música estão intimamente atreladas ao surgimento da notação musical, principalmente aquelas relacionadas passagem da monofonia à polifonia (DAHL, 2009; GROUT, PALISCA, 1994; BENT, 2001). Sendo assim, vemos que a forma como a expressão musical da vida interior humana se desenvolveu historicamente - algo que corresponde, em última instância, ao processo de produção e reprodução da sociedade como um todo - está ligada à capacidade de escrita e leitura da música. A aprendizagem dessa escrita e leitura, então, não está deslocada da vida social, mas significa precisamente o contrário: por meio dela que podemos alçar os mais altos níveis de desenvolvimento da música, os quais, no limite, correspondem aos mais altos níveis de desenvolvimento humano. Tudo isso fica mais claro se entendermos que a escrita musical significa uma forma mais consciente de relação com a música, e, portanto, como o próprio ser humano, tal qual a linguagem escrita e a fala. Como nos aponta Vygotski (1993, p. 232), 
Os signos da linguagem escrita e seu emprego são assimilados pela criança consciente e voluntariamente, diferenciando-se da utilização e assimilação inconsciente do aspecto sonoro da linguagem. A linguagem escrita obriga a criança a atura de um modo mais intelectual. Obriga-lhe a tomar consciência do próprio processo da fala.

Novamente, foge dos nossos limites estabelecer aqui as relações entre os desenvolvimentos da notação musical, da música e do ser humano. Neste trabalho, somente tomamos a notação musical como um exemplo da necessidade de considerar a música em suas especificidades como objetivação humana para poder compreender a dimensão política de seu ensino. Se retomarmos as considerações de Saviani sobre educação e política, o sentido político no ensino de elementos, como a notação musical, emerge claramente.

Como vimos, partindo da natureza específica da educação e da política como práticas sociais, Saviani conclui que quanto mais a educação se efetivar como prática especificamente pedagógica, mais ela se potencializa como uma prática política. Isso porque a dimensão política da prática educativa envolve a apropriação dos instrumentos culturais pelos alunos. Neste sentido, o aprendizado da notação musical não significa somente a aquisição da capacidade de escrita e de leitura de uma partitura, mas também o domínio dos elementos estruturais da música, uma via para uma relação mais consciente com a riqueza humana contida nas obras musicais.

A dimensão política do ensino dos elementos propriamente musicais está ligada ao fato de que é somente por meio deles que o aluno pode se apropriar de uma riqueza subjetiva historicamente desenvolvida pela trajetória humana. Ou melhor: os elementos musicais, as notas, as escalas, os princípios da harmonia e do ritmo, os diferentes timbres e texturas etc., nada mais são que a expressão artística do desenvolvimento da vida interior humana. Apropriar-se deste conhecimento vai muito além de adquirir a capacidade de executar uma partitura. Significa acessar as problemáticas subjetivas mais profundas do indivíduo, sentir como algo seu toda vivacidade contraditória da condição humana. Sendo mais específico: um processo de humanização deste indivíduo, de estabelecimento de uma relação íntima entre a sua vida individual e a riqueza afetiva que acompanha a trajetória do ser humano. Nos termos da famosa conceituação de Saviani acerca do trabalho educativo: "o ato de produzir, direta e intencionalmente, em cada 
indivíduo singular, a humanidade que é produzida histórica e coletivamente pelo conjunto dos homens" (SAVIANI, 2008b, p. 13).

Saviani considera que o elemento central desse processo de humanização é a catarse, “o ponto culminante do processo educativo" (SAVIANI, 2008a, p. 58). Para o autor, a categoria de catarse deve ser entendida em sua acepção gramsciniana, como “elaboração superior da estrutura em superestrutura na consciência dos homens”, isto é, como "efetiva incorporação dos instrumentos culturais, transformados agora em elementos ativos de transformação social” (SAVIANI, 2008a, p. 57). Lukács observa a catarse de forma semelhante, tomando-a como cerne do processo de elevação da subjetividade individual às máximas possibilidades de desenvolvimento subjetivo construídas historicamente pela trajetória humana, o que chama de autoconsciência do desenvolvimento da humanidade (LUKÁCS, 1968).

A música, por ser um reflexo artístico especificamente voltado para a vida interior humana, para os sentimentos e emoções presentes na vida, também se difere das outras artes no que responde à catarse. O fato de que nela a obra de arte se estruture sem nenhuma referência imediatamente externa faz com que o efeito catártico esteja completamente centrado na fruição afetiva, na mobilização dos sentimentos e emoções. Tal experiência, então, se difere de qualquer vivência emocional possível na vida cotidiana. Para Lukács, na música, a interioridade humana "se realiza ou cumpre então de modo imprevisível, inimaginavelmente intensificado; sua vivência contrasta com a interioridade própria da vida normal do homem" (LUKÁCS, 1967b, p. 77). Mas tal experiência não significa outra coisa senão a apropriação, pelo indivíduo, da riqueza afetiva produzida coletivamente pela humanidade. Daí a importância da aquisição do conhecimento dos elementos estruturais específicos da música, os quais sintetizam as formas objetivas de trabalho com esse conteúdo afetivo. Fundamentando-se em Lukács, Heller discorre sobre o processo de homogeneização proporcionado pela experiência estética em termos dessa relação entre a vida individual cotidiana e a riqueza subjetiva produzida pela humanidade.

Sabemos que a vida cotidiana é heterogênea, que solicita todas as nossas capacidades em varias direções, mas nenhuma capacidade com intensidade especial. Na expressão de Georg Lukács: é o “homem 
inteiro" ["ganze Mensch"] quem intervém na cotidianidade. O que significa homogeneização? Significa, por um lado, que concentramos toda nossa atenção sobre uma única questão e "suspenderemos" qualquer outra atividade durante a execução da anterior tarefa; e, por outro lado, que empregamos nossa inteira individualidade humana na resolução dessa tarefa. Utilizaremos outra expressão de Lukács: transformamo-nos assim em um "homem inteiramente" ["Menschen ganz"]. E significa, finalmente, que esse processo não se pode realizar arbitrariamente, mas tão somente de modo tal que nossa particularidade individual se dissipe na atividade humano-genérica que escolhemos consciente e autonomamente, isto é, enquanto indivíduos. (HELLER, 2004, p. 27, grifos no original)

Mas se, por um lado, a socialização, pela escola, das ferramentas necessárias à inserção de todos os indivíduos na riqueza musical é, em si mesma, um ato político, isso não quer dizer, de forma alguma, que tal ato terá consequências diretas em termos de posicionamento político dos indivíduos. Em primeiro lugar, essas consequências diretas não existem porque é longa e complexa a cadeia de mediações entre o enriquecimento da subjetividade individual e a tomada de posições concretas perante a vida e a sociedade. Em segundo lugar, é preciso considerar que as práticas sociais relacionadas à música também estão inseridas nas contradições que marcam a sociedade capitalista, como a divisão social do trabalho, a mercantilização, os modismos etc. A educação musical na escola, quanto melhor seja sua qualidade, mais conflitos terá que enfrentar com o caráter profundamente alienante da cotidianidade capitalista contemporânea. Ensinar música é também parte da luta ideológica. Em terceiro lugar, uma das formas de alienação produzidas pela sociedade capitalista é a fragmentação do ser social em esferas separadas e conflitantes entre si, o que acarreta também a fragmentação da vida das pessoas e, no limite, a fragmentação da própria individualidade. Marx já havia caracterizado esse problema da seguinte maneira:

Se pergunto ao economista: obedeço às leis econômicas se consigo dinheiro com a entrega, com a venda de meu corpo ao prazer alheio? (os operários fabris em França chamam a prostituição de suas esposas e filhas de enésima hora de trabalho, o que é literalmente certo); não atuo de modo econômico ao vender meu amigo aos marroquinos? (e a venda direta dos homens na qualidade de comércio de recrutas, etc., tem lugar em todos os países civilizados), assim o economista me responde: não ages contra minhas leis, mas olha o que dizem a senhora Moral e a senhora Religião; minha moral e minha religião econômicas não têm nada que censurar-te. Mas em quem tenho eu que acreditar então, na 
economia política ou na moral? A moral da economia política é o ganho, o trabalho e a poupança, a sobriedade, mas a economia política promete satisfazer as minhas necessidades. A economia política da moral é a riqueza de boa consciência, de virtude etc. Mas como posso ser virtuoso, se não sou? Como posso ter boa consciência, se não sei nada? Tudo isso está fundado na essência da alienação: cada uma aplica-me uma medida diferente e oposta, a moral aplica-me uma e a economia política outra, porque cada uma destas é uma determinada alienação do homem e fixa um círculo particular da atividade essencial alienada; cada uma delas se relaciona de forma alienada com a outra alienação. (MARX, 1978, p. 19)

Além de todos esses aspectos que tornam bastante complexas e, por vezes, problemáticas, as relações entre a música e a vida, o caráter altamente mediado das relações entre educação musical e prática social decorrem também da própria especificidade da música perante as outras artes. O fato de que a música estabelece seu meio homogêneo única e exclusivamente a favor da mobilização dos sentimentos e emoções internalizados, sem qualquer relação direta com as coisas observáveis na realidade objetiva, torna menos identificável as transformações do indivíduo. Em outras palavras, uma vez que se trata de um reflexo mais voltado "para dentro" do que "para fora", ou seja, mais relacionada à vida interior do indivíduo do que à sua vida exterior, a "aplicabilidade" de uma experiência estética musical ou do conhecimento musical apropriado na vida externa desse indivíduo é também menos constatável. Para Lukács (1967b, p. 76-77),

Precisamente por isso é também muito mais difícil a passagem ao Depois. Como se vive algo que não é vivenciável em outros campos - e não somente uma intensificação das vivências débeis e dispersas da vida comum, como ocorre nas demais artes -, a "aplicação" à vida, a mutação da catarse estética em suas consequências éticas, na conduta, é muito mais difícil.

Por outro lado, esta relação indireta entre o ensino de determinado conteúdo e seu papel na transformação da prática social do indivíduo não é uma exclusividade da música. Um conhecimento científico matemático, por exemplo, pode ser tão abstrato e distante do cotidiano que dificilmente encontraremos uma utilidade prática imediata para ele em nosso dia-a-dia. Isso não quer dizer, contudo, que esse conhecimento não atue de forma transformadora na vida de quem dele se apropria, isso se considerarmos que tal transformação ultrapassa em muito o caráter utilitário e pragmático da vida cotidiana. 
Como nos mostra Duarte (2016, p. 16), “é um erro e uma ingenuidade esperar mudanças imediatas e facilmente visíveis da visão de mundo dos alunos a partir de cada tópico dos conteúdos escolares". O autor expõe a inconsistência dessa perspectiva imediatista fazendo uma crítica à tão propalada separação entre ensinar e educar:

Ensinar conteúdos escolares como ciências, história, geografia, artes, educação física, língua portuguesa e matemática é ensinar as concepções de mundo veiculadas por esses conhecimentos, ou seja, é educar. Por menos explícitas que sejam as concepções de mundo presentes nos conhecimentos ensinados na escola, elas sempre existem, o que faz do ensino desses conhecimentos sempre um ato educativo, o que desautoriza a afirmação de que ensinar não é educar. Quando a pedagogia histórico-crítica é adjetivada, por seus opositores, como "conteudista", trata-se da acusação de que a preocupação com o ensino dos conteúdos escolares descuidaria do sentido que esses conteúdos teriam ou não para a vida real dos alunos. A adjetivação pejorativa resumida na palavra "conteudista" assume o pressuposto de que os conhecimentos podem ser acumulados na mente de um indivíduo sem que isso gere impactos significativos sobre sua prática social. Ocorre que esse pressuposto não resiste a uma análise que, em vez de pautar-se no estabelecimento de relações imediatas e pragmáticas entre pensamento e ação, compreenda as relações, constituídas histórica e dialeticamente, entre conhecimentos, concepções de mundo e prática social. (DUARTE, 2016, p. 95-96)

Esse excerto mostra que o papel da educação escolar na sociedade não se limita a atender as necessidades pragmáticas e imediatas de nosso cotidiano, mas sim formar as bases de uma concepção de mundo que fundamenta a prática social do indivíduo. É claro que tais necessidades mais imediatas da vida podem ser incluídas na formulação de um currículo escolar, mas limitarmos o horizonte curricular a tal imediatismo esvazia o próprio sentido da educação escolar, reduzindo também sua importância política na transformação da sociedade. É necessário que compreendamos as relações indiretas e altamente mediadas entre os conteúdos escolares e a prática social dos alunos que deles se apropriam. Isso se mostra ainda mais importante no caso da música e de todas as outras artes, pois, afinal, se nos restringirmos a uma perspectiva pragmática e imediatista, para que serve a música no nosso dia-a-dia?

Todas as discussões desenvolvidas neste trabalho não visam resolver a problemática das relações entre a música, seu ensino e seu efeito transformativo da prática social - como se fosse possível compor uma "receita" para um ensino da música 
com vistas à superação das contradições sociais. Nosso objetivo foi simplesmente abordar tal problemática sob determinados fundamentos teóricos, provenientes tanto da estética marxista, quanto da pedagogia histórico-crítica. Acreditamos, assim, ter defendido nossa tese inicial de que a compreensão das especificidades da música como objetivação humana contribui para o entendimento da dimensão política do ensino de música. Em resumo, a questão em tela é a da dialética entre a música, como conteúdo escolar, e sua influência na prática política como uma relação indireta, altamente mediada, em parte pela própria natureza da música, em parte pela não imediaticidade entre um conteúdo escolar e a transformação da prática social e, em parte, pelas próprias circunstâncias sociais contemporâneas. Acreditamos que somente pelo entendimento desses processos pode-se chegar à compreensão do sentido político do ensino de música na educação escolar.

\section{Referências}

BENT, Ian David et al. (Notation). In: GROVE Music Online. Oxford Music Online. Oxford University Press, 2001. Disponível em:

<http://www.oxfordmusiconline.com/view/10.1093/gmo/9781561592630.001.0001/omo9781561592630-e-0000020114> Acesso: 26 de maio de 2018.

BOURGAULT, Sophie. Music and pedagogy in the Platonic City. The Journal of Aesthetic Education, v. 46, n. 1, p. 59-72, spring 2012.

DAHL, Per. The rise and fall of literacy in classical music: an essay on musical notation.

Fontes Artis Musicae, v. 56, n. 1, p. 66-76, jan., 2009.

DUARTE, Newton. A individualidade para-si: contribuição a uma teoria histórico-social da formação do indivíduo. $3^{\text {a }}$ ed., rev. Campinas: Autores Associados, 2013.

DUARTE, Newton. Os conteúdos escolares e a ressureição dos mortos: contribuição à teoria histórico-crítica do currículo. Campinas, SP: Autores Associados, 2016. 
GROUT, Donald Jay; PALISCA, Claude Victor. História da música ocidental. Lisboa: Gradiva, 1994.

HELLER, Agnes. O cotidiano e a história. 7. ed. São Paulo: Paz e Terra, 2004.

KOSIK, Karel. Dialética do concreto. Rio de Janeiro: Paz e Terra, 1976, $2^{\text {a }}$ ed.

LUKÁCS, György. Estética: la peculiaridad de lo estético. Cuestiones preliminares y de principio. Tradução: Manuel Sacritán. v.1. Barcelona: Grijalbo, 1966a.

LUKÁCS, György. Estética: la peculiaridad de lo estético. Problemas de la mímesis. Tradução: Manuel Sacritán. v. 2. Barcelona: Grijalbo, 1966 b.

LUKÁCS, György. Estética: la peculiaridad de lo estético. Categorías psicológicas y filosóficas básicas de lo estético. Tradução: Manuel Sacritán. v. 3. Barcelona: Grijalbo, $1967 a$.

LUKÁCS, György. Estética: la peculiaridad de lo estético. Cuestiones liminares de lo estético. Tradução: Manuel Sacritán. v. 4. Barcelona: Grijalbo, $1967 b$.

LUKÁCS, György. Introdução a uma estética marxista. 2. ed. Rio de Janeiro: Civilização Brasileira, 1968.

LUKÁCS, György. Introdução aos escritos estéticos de Marx e Engels. In: MARX, Karl; ENGELS, Friedrich. Cultura, arte e literatura: textos escolhidos. São Paulo: Expressão Popular, 2010.

MARTINS, Lígia Marcia. O desenvolvimento do psiquismo e a educação escolar: contribuições à luz da psicologia histórico-cultural e da pedagogia histórico-crítica. Campinas, SP: Autores Associados, 2013.

MARX, Karl. Manuscritos econômico-filosóficos e outros textos escolhidos. Tradução: José Carlos Bruni et al. 2. ed. São Paulo: Abril Cultural, 1978.

MATHIESEN, Thomas. Harmonia and Ethos in Ancient Greek Music. The Journal of Musicology. University of California Press. v. 3, n. 3, p. 264-279, summer, 1984.

SAVIANI, Dermeval. Escola e democracia. Edição comemorativa. Campinas: Autores Associados, 2008a.

SAVIANI, Dermeval. Pedagogia histórico-crítica: primeiras aproximações. $10^{\mathrm{a}}$ ed. Campinas: Autores Associados, 2008b.

SCHAEFFER, Pierre. Tratado de los objetos musicales. Trad.: Araceli C. de Diego. Madrid: Alianza Editorial, 1988.

SCHAFER, Richard Murray. O ouvido pensante. Trad. Marisa Trench de Oliveira Fonterrada. São Paulo: Editora UNESP, 1991. 
SCHAFER, Richard Murray. A afinação do mundo. Tradução: Marisa Trench de Oliveira Fonterrada. $2^{\text {a }}$ ed. São Paulo: Editora UNESP, 2011.

SCHRADE, Leo. Music in the Philosophy of Boethius. The Musical Quarterly, v. 33, n. 2, p. 188-200, april 1947.

VYGOTSKI, Lev Semenovitch. Obras escogidas. Madrid, Visor, Tomo II, 1993.

Recebido em: 19/10/2018

Aprovado em: 09/11/2018

Universidade do Estado de Santa Catarina - UDESC Programa de Pós-Graduação em Educação - PPGE Revista Linhas

Volume 20 - Número 42 - Ano 2019 revistalinhas@gmail.com 